\title{
The prevalence and incidence, resource use and financial costs of treating people with attention deficit/hyperactivity disorder (ADHD) in the United Kingdom (1998 to 2010)
}

\author{
Sarah E Holden ${ }^{1}$, Sara Jenkins-Jones ${ }^{2}$, Chris D Poole ${ }^{1}$, Christopher LI Morgan² ${ }^{2}$ David Coghill ${ }^{3}$ and Craig J Currie ${ }^{1 *}$
}

\begin{abstract}
Background: Attention deficit/hyperactivity disorder (ADHD) is a common disorder that often presents in childhood and is associated with increased healthcare resource use. The aims of this study were to characterise the epidemiology of diagnosed ADHD in the UK and determine the resource use and financial costs of care.

Methods: For this retrospective, observational cohort study, patients newly diagnosed with ADHD between 1998 and 2010 were identified from the UK Clinical Practice Research Datalink (CPRD) and matched to a randomly drawn control group without a diagnosis of ADHD. The prevalence and incidence of diagnosed ADHD were calculated. Resource utilisation and corresponding financial costs post-diagnosis were estimated for general practice contacts, investigations, prescriptions, outpatient appointments, and inpatient admissions.

Results: Incidence of diagnosed ADHD (and percentage change using 1998 as a reference) increased from 6.9 per 100,000 population in 1998 to 12.2 per 100,000 (78\%) in 2007 and then fell to 9.9 per 100,000 (44\%) by 2009. The corresponding prevalence figures were 30.5, 88.9 (192\%) and 81.5 (167\%) per 100,000. Incidence and prevalence were higher in males than females. Mean annual total healthcare costs were higher for ADHD cases than controls ( $£ 1,327$ versus $£ 328$ for year $1, £ 1,196$ vs. $£ 337$ for year $2, £ 1,148$ vs. $£ 316$ for year $3, £ 1,126$ vs. $£ 325$ for year 4 , and $£ 1,112$ vs. $£ 361$ for year 5).

Conclusions: The prevalence of diagnosed ADHD in routine practice in the UK was notably lower than in previous reports, and both prevalence and incidence of diagnosed ADHD in primary care have fallen since 2007. Financial costs were more than four times higher in those with ADHD than in those without ADHD.
\end{abstract}

Keywords: ADHD, CPRD, Prevalence, Incidence, Healthcare cost

\section{Background}

Attention deficit/hyperactivity disorder (ADHD) is common and more likely to affect boys than girls, with an estimated prevalence in the UK of $3.6 \%$ and $0.9 \%$, respectively, in children aged 5-15 years, using DSM-IV criteria [1]. Anecdotally, there is a commonly held belief that the prevalence of ADHD has risen markedly over the previous 20 years, with a corresponding increase in the financial cost of medicines indicated for ADHD

\footnotetext{
* Correspondence: currie@cardiff.ac.uk

'Primary Care and Public Health, School of Medicine, The Pharma Research Centre, Cardiff Medicentre, Cardiff University, Cardiff CF14 4UJ, UK Full list of author information is available at the end of the article
}

[2,3]. ADHD is a chronic condition that is often associated with significant impairments in academic performance and social functioning $[4,5]$. Over $65 \%$ of those with ADHD also have one or more comorbid disorders. These include dyslexia, developmental coordination disorder, Tourette's syndrome, autistic spectrum disorders, conduct and oppositional defiant disorders, and substance abuse [4,6]. ADHD is also associated with disrupted parent-child relationships and increased parent stress levels $[4,7]$. Treatment costs for patients with ADHD are greater than those without [8-15].

In the UK, the National Institute for Health and Care Excellence (NICE) has recommended that diagnosis of

\section{Biomed Central}

(c) 2013 Holden et al.; licensee BioMed Central Ltd. This is an open access article distributed under the terms of the Creative Commons Attribution License (http://creativecommons.org/licenses/by/2.0), which permits unrestricted use, distribution, and reproduction in any medium, provided the original work is properly cited. 
ADHD and treatment initiation should be conducted within secondary care [16]. When medication is used the dose should also be titrated and stabilised by a specialist. Once the patient is stabilised on treatment, prescribing and monitoring can be carried out in primary care under a shared-care protocol [16]. Whilst the popular press frequently comments on increased rates of diagnosis of ADHD and questions whether ADHD is over-diagnosed and over-treated [17], data from reviews of clinical practice suggest the opposite may be true with ADHD being both under recognised and under treated [18]. There are, however, few studies characterising the epidemiology of diagnosed ADHD in the UK and the healthcare cost to the NHS of treating children both with and without ADHD.

The aim of this retrospective, observational cohort study was to characterise the incidence and prevalence of diagnosed ADHD and to determine the corresponding resource use and financial cost of care for children, adolescents, and adults with ADHD compared with a matched control group over a 12-year period to 2010 .

\section{Methods}

\section{Data sources}

Data were extracted from the CPRD (Clinical Practice Research Datalink) [19]. CPRD contains clinically rich data collected in a non-interventional manner from the daily record-keeping of primary-care physicians in the UK. These data include demographics, medical history, test results, outpatient letters, and prescriptions. There are, in total, 143 million acceptable person-years of computerised data in CPRD, and the dataset is broadly representative of the UK population. Following record-linkage to NHS hospital episode statistics (HES), CPRD additionally contains details of inpatient admissions for a proportion of practices in England. The data extract used in this study includes records up to June 2012. Ethical approval for this study was granted by the CPRD Independent Scientific Advisory Committee on 1st March 2012, protocol number 12_025R2.

\section{Study population \\ Cases}

Patients were selected from CPRD if they had received two or more diagnoses for ADHD in their clinical history, or they had received at least one diagnosis of ADHD and at least one prescription for a medicine licensed for the management of ADHD. For cases where there was no prescription for an ADHD medication, the requirement of two or more diagnoses was used to avoid selecting for patients with only a provisional diagnosis recorded by the GP prior to assessment by a specialist. Under NICE guidelines, diagnosis should be made by a mental health specialist; therefore the second diagnosis is used to confirm that the patient has ADHD. A medicine used for the management of ADHD was defined as a product containing one of the following drugs: dexamfetamine, methylphenidate or atomoxetine. Pemoline (indicated for hyperkinetic syndrome but not generally available in the UK after 1997) [20] and modafinil (not licensed for the management of ADHD nor for use in children) [21] were not used for case selection. The study index date was the date of ADHD presentation, taken as the earlier of their first recorded diagnosis date for ADHD or their first prescription for a medicine used in the management of ADHD.

Cases were excluded from the analysis if they had a history of narcolepsy. In order to identify incident cases only, cases with less than six months' "wash-in" for relevant parameters were also excluded (Additional file 1: Figure S1). No exclusion criteria based on age were implemented; however, the results were split by age group (0-5, 6-17 and $\geq 18$ years) because licensed and recommended treatments vary by age. For example, atomoxetine and methylphenidate are not licensed in children younger than 6 years. In addition, the NICE guidelines do not recommend pharmacological treatment in preschool children. After school leaving age $(\leq 18)$, NICE recommends that patients should be reassessed before transfer to adult services to ensure that continuing treatment into adulthood is still warranted and to facilitate transition. In addition, only atomoxetine is licensed for the treatment of ADHD in adults.

\section{Controls}

The healthcare costs and resource use of the ADHD group were compared to a randomly drawn control group of patients matched on year of birth, gender and GP practice. Control patients had no history of ADHD and had received no prescription for a medication indicated for ADHD.

Table 1 Baseline characteristics for cases and controls

\begin{tabular}{llcc}
\hline Age group & Parameter & Cases & References \\
\hline All ages & $\mathrm{N}$ & 3,229 & 7,429 \\
& Males, n (\%) & $2,759(85 \%)$ & $6,354(86 \%)$ \\
& Females, n (\%) & $470(15 \%)$ & $1,075(14 \%)$ \\
& Age, mean (sd), & $10.4(5.9)$ & $10.4(6.1)$ \\
& years & & \\
Aged 6 to 17 years & $\mathrm{N}$ & 2,873 & 6,598 \\
at index date & Males, n (\%) & $2,487(87 \%)$ & $5,707(86 \%)$ \\
& Females, n (\%) & $386(13 \%)$ & $891(14 \%)$ \\
& Age, mean (sd), & $9.8(2.8)$ & $9.8(2.8)$ \\
Aged $\geq 18$ years & years & & 300 \\
at index date & N & & 141 \\
& Males, n (\%) & $86(61 \%)$ & $183(61 \%)$ \\
& Females, n (\%) & $55(39 \%)$ & $117(39 \%)$ \\
& Age, mean (sd), & $31.7(10.7)$ & $33.2(12.3)$ \\
& years & & \\
\hline
\end{tabular}


Cases and controls were included in an annual cost calculation if they had a complete year's observation for the year in question in both CPRD and CPRD-linked HES. Therefore, patients were excluded from the analysis of the costs for year 1 if they had less than 12 months' observations from the index date to the last date of any prescription or the censor date, whichever was earlier. For year 2, patients were excluded if they did not have a complete year of data from 366 days to 730 days following their index date. The same rule was applied for the calculation of costs for years three through five.

\section{Diagnostic incidence of ADHD}

The incidence of diagnosed ADHD was calculated by dividing the number of new cases of ADHD each year by the number of person-years at risk in the CPRD data set for the same year (including those registered but with no GP attendance).

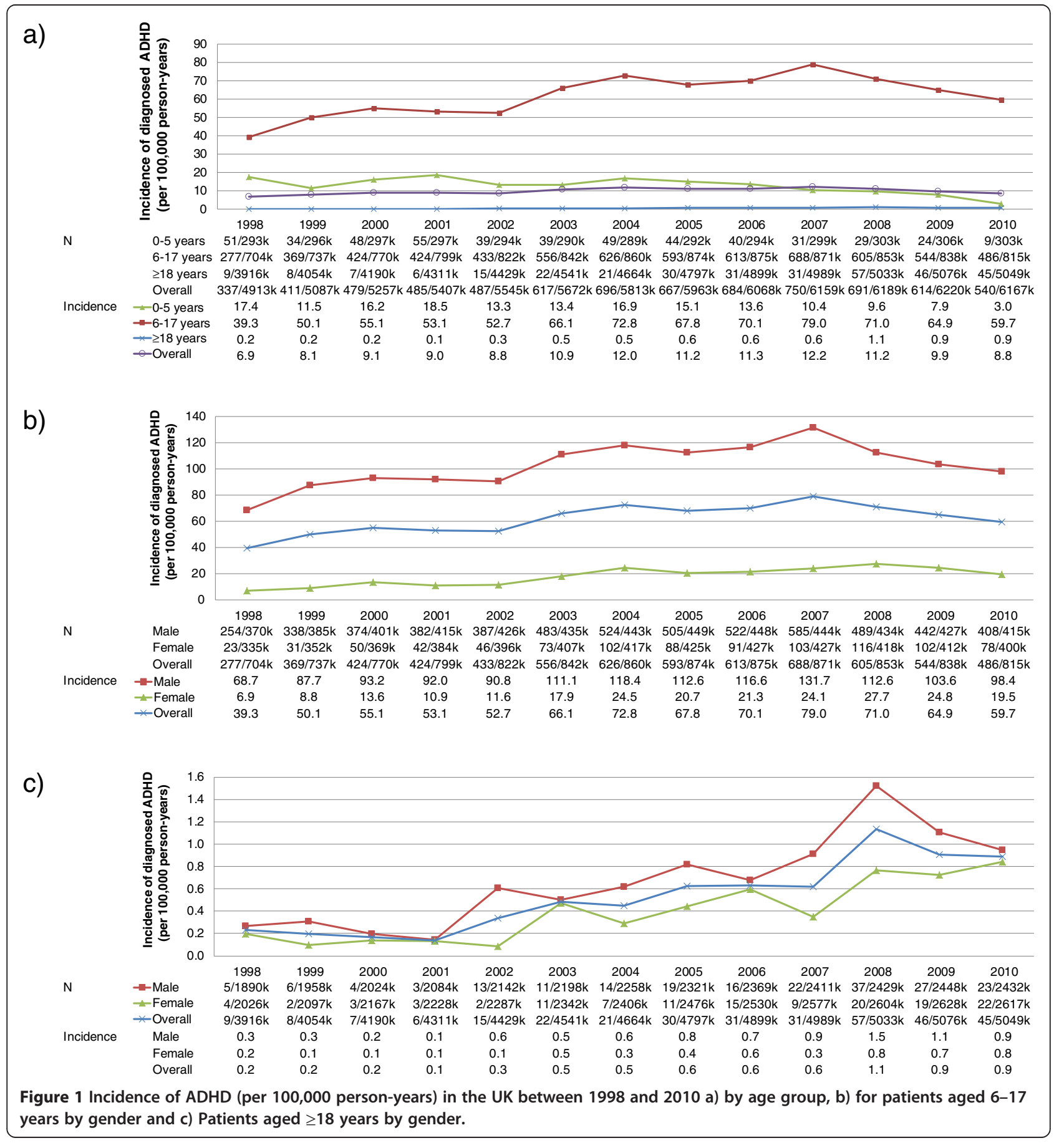




\section{Denominator}

The number of person-years of people without ADHD was calculated by adding the number of days each patient had been present in the CPRD database for each specific year. Patients were included in the denominator until the earliest of their death date, transferred-out date, or ADHD presentation date. Patients who did not meet the selection criteria for the study were included in the denominator data.

\section{Numerator}

On the date of ADHD presentation, cases were included in the numerator portion of the incidence calculation for that specific year.

The incidence of treated ADHD was calculated using the same method. For calculations of incidence by gender and age group only those patients of the appropriate age or gender were included in the numerator and denominator parts of the incidence calculation.

\section{Diagnostic prevalence of ADHD}

The point prevalence of diagnosed ADHD was calculated each year by dividing the number of patients with ADHD on 1st July (mid-year point) of that year by the total number of patients registered in CPRD on that date.

\section{Numerator}

A patient was included as a prevalent case if they met the selection criteria for the study, their ADHD presentation date was prior to 1st July of the specific year, and the later of their last ADHD diagnosis or last prescription for an ADHD medication was after 1st of July of that year. However, in order to allow for an adequate washout period (more than 12 months), prevalence was only calculated from 1998 to 2009. A washout period was considered necessary as the chance of receiving a diagnosis for ADHD following the mid-year point reduces as the time between the mid-year point and the last collection date for the database becomes shorter.

\section{Denominator}

This was the total number of patients registered in CPRD on 1st July of the specific year.

For calculations of prevalence by gender and age group only those patients of the appropriate age and gender were included in the numerator and denominator parts of the prevalence calculation.

\section{Estimation of the cost of healthcare in CPRD}

Resource use and costs were applied to the following areas of patient care: prescriptions, primary-care contacts, investigations, hospital admissions, and outpatient appointments. The aim was to calculate the overall cost of treating an individual with ADHD not just the cost of treating the ADHD itself. Annual costs for the first five years following the index date were estimated.

\section{Prescription costs}

Each prescription item listed in CPRD was attributed a net ingredient cost (NIC) from the corresponding year of the Prescription Cost Analysis (PCA) [22,23]. The NIC refers to the cost of the drug before discounts and does not include any dispensing costs or fees [24]. All NICs were adjusted for inflation to 2011 prices [25]. Either an exact match was made or the British National Formulary (BNF) taxonomy was utilised to attribute an average NIC per item for the BNF sub-paragraph, section or chapter.

\section{Outpatient attendance costs}

Outpatient events were identified from CPRD's consultation table if they had a consultation type indicative or suggestive of an outpatient appointment. The outpatient department and whether the consultation was a first or

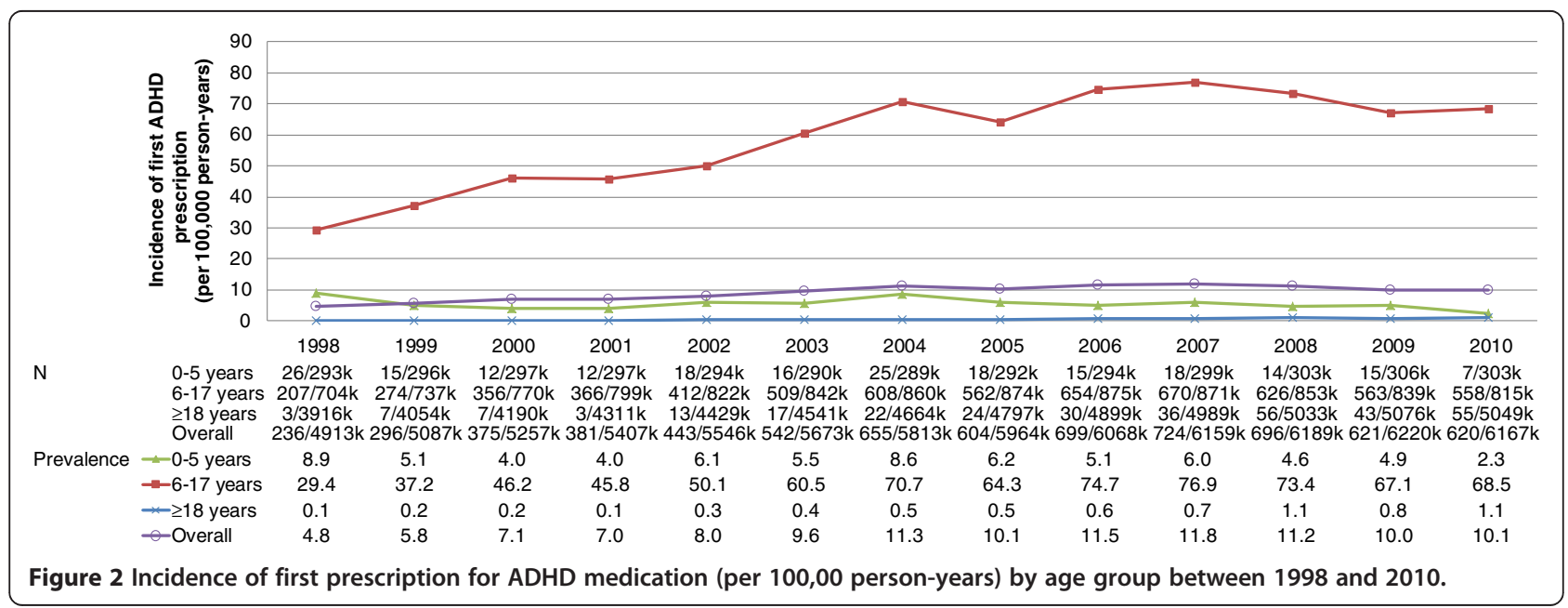




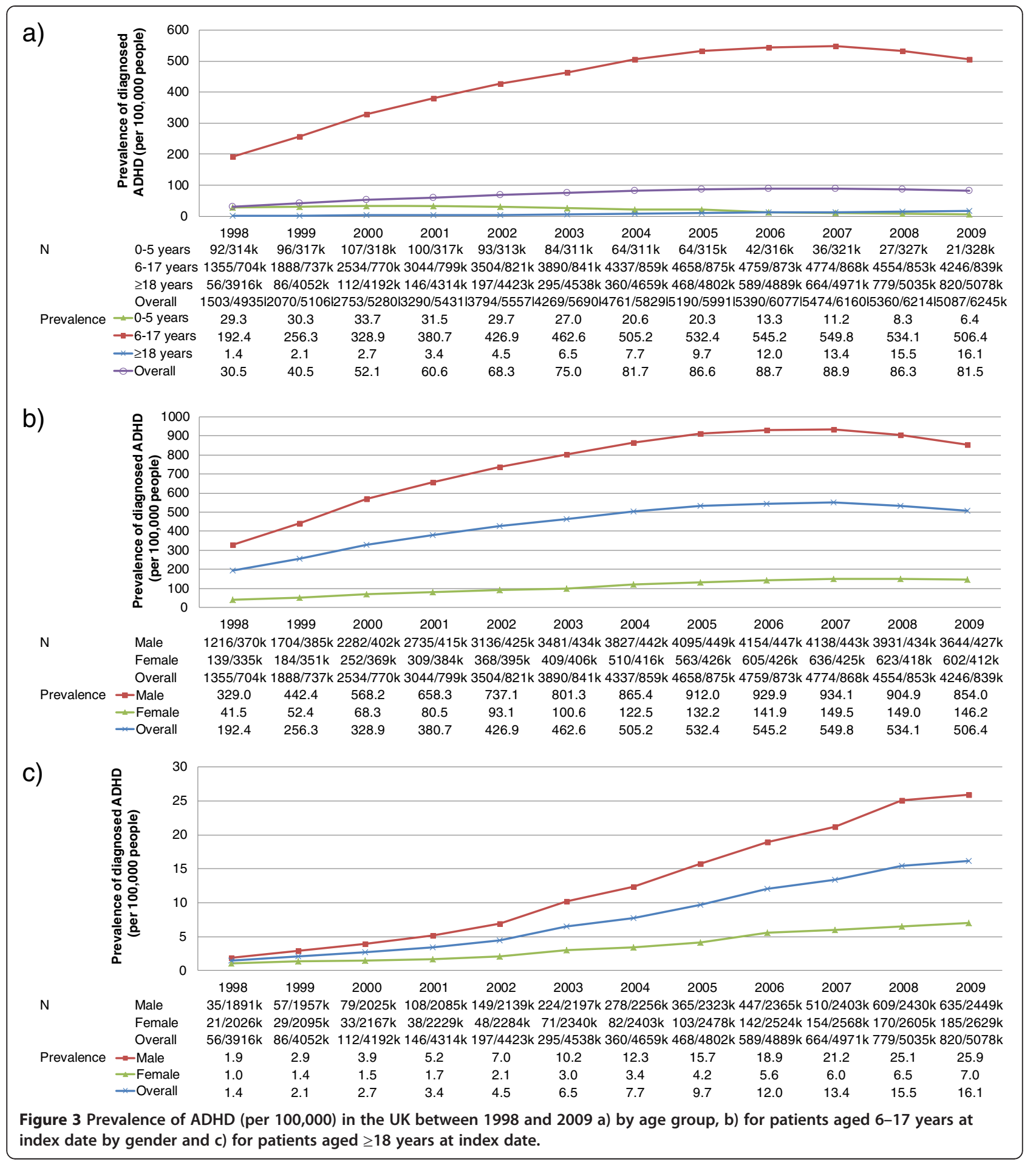

follow-up visit were used to allocate each appointment to an outpatient tariff [26].

\section{Cost of investigations}

Investigations were identified, including both pathology and diagnostic services. Several reference sources were used to attribute a cost to these tests [26-29]. Laboratory tests carried out on the same day were grouped into test panels where appropriate in order to take account of any reduction in cost of carrying out more than one test at the same time [30].

\section{Primary-care consultations}

Each consultation was classified by consultation type (e.g. surgery appointment, clinic, home visit, telephone 
consultation) and staff type (e.g. GP, practice nurse, mental health nurse, district nurse) and then assigned an average cost as listed in the Unit Cost of Health and Social Care 2010 from the Personal Social Services Research Unit (PSSRU) [31]. Where average cost per hour was the only cost published in the Unit Costs of Health and Social Care, the UK GP workload survey [32] was utilised in order to determine the average length of the consultation. From this figure, the average cost per consultation could be calculated.

\section{Hospital admissions}

CPRD-linked HES records allowed us to cost inpatient admissions. From the care pathway outlined in the NICE guidelines for ADHD, we would not expect patients to be routinely admitted to hospital as a direct result of their ADHD [16]. However, children and adolescents with ADHD may be more prone to other problems requiring admission such as accidents or self-harm [16].

Data from inpatient admissions recorded in HES were processed into Healthcare Resource Groups (HRGs) using HRG-4 grouper [33]. The HRGs were then matched to NHS Reference Costs 2009-2010 [34]. It was not possible to differentiate between elective or emergency day-case admissions from the data available, and so costs were averaged by ratio of each admission type. Data on procedures were not available and so all costs were inflated by 17.5\%: the average difference between procedural and non-procedural admissions.

\section{Results}

3,229 cases with ADHD and 7,429 matched control patients were identified in CPRD (Table 1). The mean age at diagnosis was 10.4 (sd 5.9) years for cases and 10.4 (6.1) years for controls, and $85 \%$ of cases and $86 \%$ of controls were male. Baseline characteristics are detailed in Table 1.

\section{Incidence and prevalence of diagnosed ADHD}

In 1998, the annual incidence of diagnosed ADHD across all ages was 6.9 cases per 100,000 population (per100k; Figure 1a). This peaked in 2007, with 12.2 cases per100k (an increase of 78\%). Overall, the incidence of diagnosed ADHD had fallen by 2010 to 8.8 per100k (an increase of $28 \%$ relative to 1998). The incidence of diagnosed ADHD in children and adolescents aged 6 to 17 years increased from 39.3 per100k in 1998 to 79.0 per100k (101\% increase using 1998 as a reference) in 2007 before decreasing to 59.7 per100k (52\% increase from 1998) in 2010 (Figure 1b). In 1998, the incidence of ADHD was 10 times higher in males than in females for patients aged 6 to 17 years but only five times higher in 2010 . The incidence rate in adults was much lower than for patients aged 6 to 17 years and increased from 0.2 per100k in 1998 to 1.1 per100k (393\% increase from 1998) in 2008 before falling to 0.9 per100k (288\%) in 2010 (Figure 1c). For adults, the incidence rate in males was 1.3 times higher than in females in 1998 but only 1.1 times higher in 2009. The incidence of treated ADHD was 4.8 per100k in 1998 and reached a peak of 11.8 per100k (145\%) in 2007 (Figure 2) before decreasing to 10.1 per100k (109\%) in 2010.

The overall prevalence (and percentage change using 1998 as the reference) of diagnosed ADHD increased from 30.5 per100k in 1998 to 88.9 per100k (192\%) in 2007 (Figure 3a). The prevalence then fell to 81.5 per100k (167\%) in 2009 (Figure 3a). The diagnosed prevalence of ADHD was much higher in children aged 6 to 17 years than in adults. However, the prevalence increased in both groups between 1998 and 2007. In 1998,

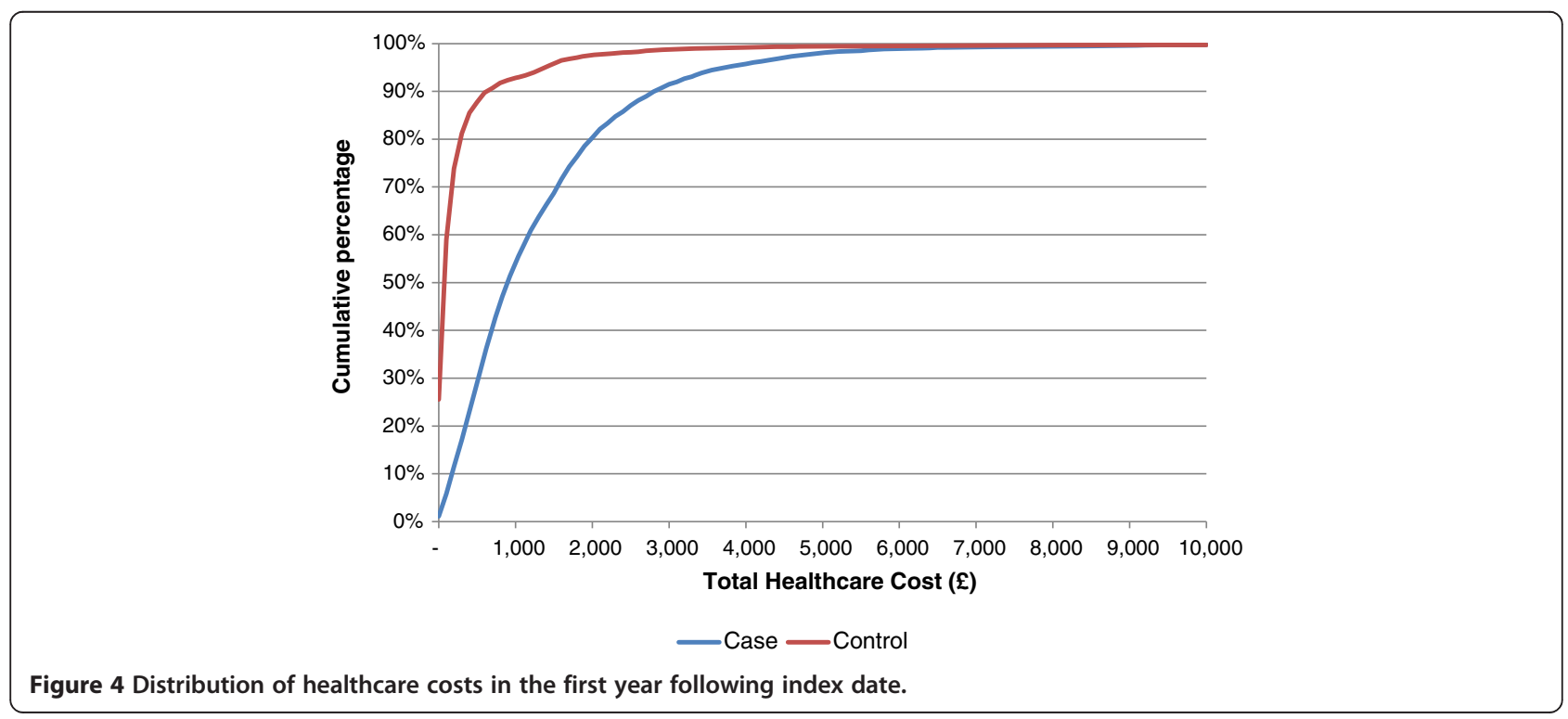


Table 2 Total NHS healthcare costs for cases and controls in the first year following index date

\begin{tabular}{|c|c|c|c|c|c|c|c|}
\hline Age group & Resource Type & Group & Mean & $\begin{array}{l}\text { Standard } \\
\text { Deviation }\end{array}$ & Median & Percentile 25 & Percentile 75 \\
\hline \multirow[t]{12}{*}{ All ages } & \multirow[t]{2}{*}{ Investigations } & Case & $£ 11$ & $£ 38$ & $£ 0$ & $£ 0$ & $£ 0$ \\
\hline & & Control & $£ 8$ & $£ 35$ & $£ 0$ & $£ 0$ & $£ 0$ \\
\hline & \multirow{2}{*}{$\begin{array}{l}\text { Primary-Care } \\
\text { Appointments }\end{array}$} & Case & $£ 210$ & $£ 187$ & $£ 166$ & $£ 81$ & $£ 279$ \\
\hline & & Control & $£ 75$ & $£ 100$ & $£ 31$ & $£ 0$ & $£ 93$ \\
\hline & \multirow[t]{2}{*}{ Prescriptions } & Case & $£ 308$ & $£ 384$ & $£ 185$ & $£ 53$ & $£ 422$ \\
\hline & & Control & $£ 37$ & $£ 312$ & $£ 2$ & $£ 0$ & $£ 15$ \\
\hline & \multirow{2}{*}{$\begin{array}{l}\text { Outpatient } \\
\text { Attendances }\end{array}$} & Case & $£ 580$ & $£ 882$ & $£ 0$ & $£ 0$ & $£ 906$ \\
\hline & & Control & $£ 64$ & $£ 255$ & $£ 0$ & $£ 0$ & $£ 0$ \\
\hline & \multirow{2}{*}{$\begin{array}{l}\text { Hospital } \\
\text { Admissions }\end{array}$} & Case & $£ 218$ & $£ 1,770$ & $£ 0$ & $£ 0$ & $£ 0$ \\
\hline & & Control & $£ 144$ & $£ 2,068$ & $£ 0$ & $£ 0$ & $£ 0$ \\
\hline & \multirow[t]{2}{*}{ Total } & Case & $£ 1,327$ & $£ 2,114$ & $£ 890$ & $£ 427$ & $£ 1,742$ \\
\hline & & Control & $£ 328$ & $£ 2,248$ & $£ 69$ & $£ 0$ & $£ 214$ \\
\hline \multirow{12}{*}{$\begin{array}{l}\text { Aged } 6 \text { to } 17 \text { years } \\
\text { at index date }\end{array}$} & \multirow[t]{2}{*}{ Investigations } & Case & $£ 10$ & $£ 34$ & $£ 0$ & $£ 0$ & $£ 0$ \\
\hline & & Control & $£ 8$ & $£ 34$ & $£ 0$ & $£ 0$ & $£ 0$ \\
\hline & \multirow{2}{*}{$\begin{array}{l}\text { Primary-Care } \\
\text { Appointments }\end{array}$} & Case & $£ 199$ & $£ 171$ & $£ 155$ & $£ 73$ & $£ 279$ \\
\hline & & Control & $£ 70$ & $£ 92$ & $£ 31$ & $£ 0$ & $£ 93$ \\
\hline & \multirow[t]{2}{*}{ Prescriptions } & Case & $£ 306$ & $£ 363$ & $£ 192$ & $£ 57$ & $£ 423$ \\
\hline & & Control & $£ 37$ & $£ 326$ & $£ 2$ & $£ 0$ & $£ 14$ \\
\hline & \multirow{2}{*}{$\begin{array}{l}\text { Outpatient } \\
\text { Attendances }\end{array}$} & Case & $£ 572$ & $£ 865$ & $£ 0$ & $£ 0$ & $£ 899$ \\
\hline & & Control & $£ 62$ & $£ 253$ & $£ 0$ & $£ 0$ & $£ 0$ \\
\hline & \multirow{2}{*}{$\begin{array}{l}\text { Hospital } \\
\text { Admissions }\end{array}$} & Case & $£ 203$ & $£ 1,838$ & $£ 0$ & $£ 0$ & $£ 0$ \\
\hline & & Control & $£ 139$ & $£ 2,171$ & $£ 0$ & $£ 0$ & $£ 0$ \\
\hline & \multirow[t]{2}{*}{ Total } & Case & $£ 1,290$ & $£ 2,119$ & $£ 879$ & $£ 425$ & $£ 1,689$ \\
\hline & & Control & $£ 315$ & $£ 2,354$ & $£ 64$ & $£ 0$ & $£ 198$ \\
\hline \multirow{12}{*}{$\begin{array}{l}\text { Aged } \geq 18 \text { years } \\
\text { at index date }\end{array}$} & \multirow[t]{2}{*}{ Investigations } & Case & $£ 42$ & $£ 93$ & $£ 2$ & $£ 0$ & $£ 38$ \\
\hline & & Control & $£ 24$ & $£ 67$ & $£ 0$ & $£ 0$ & $£ 17$ \\
\hline & \multirow{2}{*}{$\begin{array}{l}\text { Primary-Care } \\
\text { Appointments }\end{array}$} & Case & $£ 375$ & $£ 326$ & $£ 298$ & $£ 186$ & $£ 478$ \\
\hline & & Control & $£ 137$ & $£ 188$ & $£ 75$ & $£ 31$ & $£ 186$ \\
\hline & \multirow[t]{2}{*}{ Prescriptions } & Case & $£ 488$ & $£ 580$ & $£ 304$ & $£ 113$ & $£ 603$ \\
\hline & & Control & $£ 65$ & $£ 242$ & $£ 6$ & $£ 0$ & $£ 36$ \\
\hline & \multirow{2}{*}{$\begin{array}{l}\text { Outpatient } \\
\text { Attendances }\end{array}$} & Case & $£ 614$ & $£ 1,065$ & $£ 87$ & $£ 0$ & $£ 753$ \\
\hline & & Control & $£ 83$ & $£ 316$ & $£ 0$ & $£ 0$ & $£ 0$ \\
\hline & \multirow{2}{*}{$\begin{array}{l}\text { Hospital } \\
\text { Admissions }\end{array}$} & Case & $£ 324$ & $£ 1,002$ & $£ 0$ & $£ 0$ & $£ 0$ \\
\hline & & Control & $£ 241$ & $£ 1,065$ & $£ 0$ & $£ 0$ & $£ 0$ \\
\hline & \multirow[t]{2}{*}{ Total } & Case & $£ 1,844$ & $£ 2,118$ & $£ 1,185$ & $£ 648$ & $£ 2,365$ \\
\hline & & Control & $£ 550$ & $£ 1,460$ & $£ 130$ & $£ 31$ & $£ 427$ \\
\hline
\end{tabular}

the diagnosed prevalence of ADHD was 192.4 per100k patients aged 6 to 17 years and 1.4 per100k in adults. By 2007, the prevalence was 549.8 per100k (186\% change from 1998) in patients aged 6 to 17 years and 13.4 per100k (834\%) in adults. By 2009, the prevalence of diagnosed ADHD in patients aged 6 to 17 years had fallen to 506.4 per100k (163\%) but continued to increase to 16.1 per100k $(1,029 \%)$ in adults (Figure 3a). The prevalence of diagnosed ADHD was 7.9 and 1.8 times higher in males than in females for patients aged 6 to 17 (Figure 3b) and adults (Figure 3c), respectively, in 1998 and 5.8 and 3.7 times higher in 2010 .

\section{Resource use and costs}

All healthcare costs were positively skewed, particularly in the control group (Figure 4). Total annual cost ranged 
from $£ 0$ per year to $£ 132,765$ for the control group and $£ 0$ to $£ 91,891$ for cases. $26 \%$ of controls and $1 \%$ of cases incurred no healthcare costs at all in the first year, where the mean cost was four times higher for cases $(£ 1,327$ [sd £2,114] vs. £328 [sd £2,248], p<0.001; Table 2). The median cost (inter-quartile range) was lower than the mean cost in both groups at $£ 890(£ 427-£ 1,742)$ vs. $£ 69$ $(£ 0-£ 214)$ for cases and controls, respectively. Outpatient attendances accounted for $44 \%$ of costs for cases vs. $20 \%$ for controls (Figure 5). Specific costs were as follows: investigations ( $£ 11$ vs. $£ 8$ ), primary-care appointments ( $£ 210$ vs. $€ 75$ ), prescriptions ( $£ 308$ vs. $£ 37$ ), outpatient attendances ( $£ 580$ vs. $£ 64$ ), and hospital admissions ( $£ 218$ vs. $£ 144)$. Resource use is listed in Table 3.

The mean (sd) healthcare costs for cases and controls over the five-year period were $£ 1,196$ and $£ 337$ for year 2 , $£ 1,148$ and $£ 316$ for year $3, £ 1,126$ and $£ 325$ for year 4 , and $£ 1,112$ and $£ 361$ for year 5 , respectively (Table 4).

\section{Discussion}

In this retrospective study, the prevalence of diagnosed ADHD was notably lower than previously reported. We estimated that in 2009 the incidence of ADHD was 9.9 per100k population and the prevalence 81.5 cases per100k. Compared to a matched control group, those with ADHD had substantially increased resource use and related financial costs (four-fold).

A systematic review and meta-analysis characterising the worldwide prevalence of ADHD reported that the pooled prevalence was $5.3 \%$, with significant variability [35]. In the UK in 1999 in children aged 5-15 years, the actual prevalence of ADHD-when estimated using the Development and Well-Being Assessment (DAWBA)was $3.6 \%$ in boys and $0.9 \%$ in girls [1]. The difference between these two figures may be related to the sensitivity of the DAWBA compared with other diagnostic instruments. At $0.44 \%$ in boys and $0.05 \%$ in girls the estimates of prevalence of diagnosed ADHD in 1999 in children (6-17 years) in our study was much lower than either of these. The most likely explanation for this is that the epidemiological studies screened the population and aimed to identify both diagnosed and undiagnosed cases. In the UK only a minority of patients with ADHD currently seek or receive medical treatment for their condition [36,37]. The reason for the under-diagnosis of ADHD in the UK [38] is likely to be multifactorial. For example, parents of children with ADHD are likely to identify a problem and consult education professionals, but the presentation to primary care is limited and less than one in three children with ADHD access specialist services [37]. In addition, there is limited recognition of children at risk of ADHD in primary care [36] and uncertainty among many GPs over whether ADHD should be classed as medical disorder [39]. Even in the USA, where ADHD has been recognised longer, it was estimated that, between 2001 and 2004, less than half of the children meeting DSM-IV criteria received treatment [40]. In contrast to this, the percentage of children in the USA aged 4-17 years with a parent-reported ADHD diagnosis increased from $7.8 \%$ to $9.5 \%$ between 2003 and 2007 [41]. As the prevalence and incidence figures for this study relate to diagnosed ADHD, it is possible that
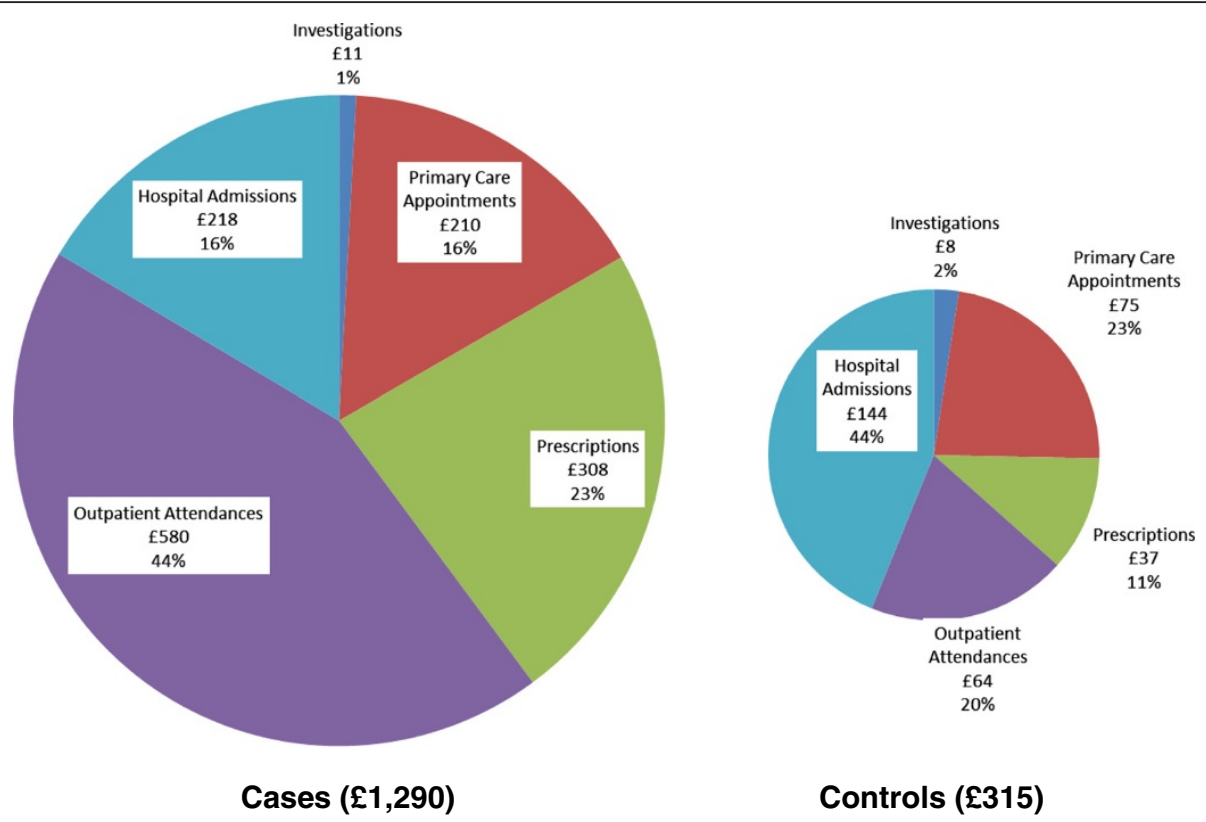

Controls (£315)

Figure 5 Breakdown of average annual costs (all ages) in the first year following index date. 
Table 3 NHS Healthcare resource use for cases and controls in the first year following index date

\begin{tabular}{|c|c|c|c|c|c|c|c|}
\hline Age group & Resource type & Group & Mean & $\begin{array}{l}\text { Standard } \\
\text { deviation }\end{array}$ & Median & Percentile 25 & Percentile 75 \\
\hline \multirow[t]{10}{*}{ All ages } & \multirow[t]{2}{*}{ Investigations } & Case & 1.3 & 4.4 & 0.0 & 0.0 & 0.0 \\
\hline & & Control & 0.8 & 3.9 & 0.0 & 0.0 & 0.0 \\
\hline & \multirow{2}{*}{$\begin{array}{l}\text { Primary-Care } \\
\text { Appointments }\end{array}$} & Case & 6.8 & 5.9 & 5.0 & 3.0 & 9.0 \\
\hline & & Control & 2.4 & 3.1 & 1.0 & 0.0 & 3.0 \\
\hline & \multirow[t]{2}{*}{ Prescriptions } & Case & 11.0 & 11.7 & 9.0 & 4.0 & 14.0 \\
\hline & & Control & 2.9 & 7.1 & 1.0 & 0.0 & 3.0 \\
\hline & \multirow{2}{*}{$\begin{array}{l}\text { Outpatient } \\
\text { Attendances }\end{array}$} & Case & 2.6 & 4.1 & 0.0 & 0.0 & 4.0 \\
\hline & & Control & 0.4 & 1.3 & 0.0 & 0.0 & 0.0 \\
\hline & \multirow{2}{*}{$\begin{array}{l}\text { Hospital } \\
\text { Admissions }\end{array}$} & Case & 0.1 & 1.1 & 0.0 & 0.0 & 0.0 \\
\hline & & Control & 0.1 & 0.7 & 0.0 & 0.0 & 0.0 \\
\hline \multirow{10}{*}{$\begin{array}{l}\text { Aged } 6 \text { to } 17 \text { years } \\
\text { at index date }\end{array}$} & \multirow[t]{2}{*}{ Investigations } & Case & 1.1 & 4.1 & 0.0 & 0.0 & 0.0 \\
\hline & & Control & 0.7 & 3.7 & 0.0 & 0.0 & 0.0 \\
\hline & \multirow{2}{*}{$\begin{array}{l}\text { Primary-Care } \\
\text { Appointments }\end{array}$} & Case & 6.4 & 5.4 & 5.0 & 2.0 & 9.0 \\
\hline & & Control & 2.2 & 2.8 & 1.0 & 0.0 & 3.0 \\
\hline & \multirow[t]{2}{*}{ Prescriptions } & Case & 10.5 & 9.6 & 9.0 & 4.0 & 14.0 \\
\hline & & Control & 2.7 & 6.8 & 1.0 & 0.0 & 3.0 \\
\hline & \multirow{2}{*}{$\begin{array}{l}\text { Outpatient } \\
\text { Attendances }\end{array}$} & Case & 2.5 & 4.0 & 0.0 & 0.0 & 4.0 \\
\hline & & Control & 0.3 & 1.3 & 0.0 & 0.0 & 0.0 \\
\hline & \multirow{2}{*}{$\begin{array}{l}\text { Hospital } \\
\text { Admissions }\end{array}$} & Case & 0.1 & 1.2 & 0.0 & 0.0 & 0.0 \\
\hline & & Control & 0.1 & 0.7 & 0.0 & 0.0 & 0.0 \\
\hline \multirow{10}{*}{$\begin{array}{l}\text { Aged } \geq 18 \text { years at } \\
\text { index date }\end{array}$} & \multirow[t]{2}{*}{ Investigations } & Case & 5.4 & 8.9 & 1.0 & 0.0 & 9.0 \\
\hline & & Control & 3.6 & 8.2 & 0.0 & 0.0 & 2.0 \\
\hline & \multirow{2}{*}{$\begin{array}{l}\text { Primary-Care } \\
\text { Appointments }\end{array}$} & Case & 12.4 & 10.5 & 10.0 & 6.0 & 16.0 \\
\hline & & Control & 4.3 & 5.8 & 2.0 & 1.0 & 6.0 \\
\hline & \multirow[t]{2}{*}{ Prescriptions } & Case & 21.1 & 28.1 & 11.0 & 5.0 & 24.0 \\
\hline & & Control & 5.1 & 12.2 & 1.0 & 0.0 & 4.0 \\
\hline & \multirow{2}{*}{$\begin{array}{l}\text { Outpatient } \\
\text { Attendances }\end{array}$} & Case & 2.8 & 4.8 & 1.0 & 0.0 & 4.0 \\
\hline & & Control & 0.4 & 1.5 & 0.0 & 0.0 & 0.0 \\
\hline & \multirow{2}{*}{$\begin{array}{l}\text { Hospital } \\
\text { Admissions }\end{array}$} & Case & 0.2 & 0.7 & 0.0 & 0.0 & 0.0 \\
\hline & & Control & 0.1 & 0.5 & 0.0 & 0.0 & 0.0 \\
\hline
\end{tabular}

any change in incidence or prevalence rates during the study period is an ascertainment effect.

The figures reported here are similar to those reported in a government-sponsored audit of ADHD services in Scotland [42]. In 2012, the overall prevalence had increased slightly to $0.7 \%$ with a similar variation across regions of Scotland and no change in the male-to-female ratio [42]. A UK study using the General Practice Research Database (GPRD; forerunner of CPRD) estimated that the prevalence of treated ADHD for patients aged 15-21 years was 0.88 per 1,000 in 1999 , increasing to 5.09 per 1,000 in 2006 [43]. A slightly higher prevalence, though in a different age range, was reported by another study: 2.6 and 5.5 per 1,000 for 1999 and 2006, respectively, in patients aged 6-17 years [43].
We found that diagnosed cases of ADHD were more common in males than in females. Epidemiological studies have also reported a greater prevalence in males, with a male-to- female ratio of 2-3:1 [35]. In adults, however, the male-to-female ratio for ADHD has been reported to be approximately equal [44]. The higher ratios reported here and in other studies of diagnostic prevalence or treatment suggest that, in the UK, girls with ADHD are even less likely to be recognised and diagnosed than boys. It is possible that this is at least partly due to the fact that that females present with different symptoms and, most importantly, that they are less likely to have coexisting oppositional or disruptive behaviours [45]. However, a firm consensus on this matter has not been reached [16]. 
Table 4 Total NHS healthcare costs for cases and controls for the first five years following index date

\begin{tabular}{|c|c|c|c|c|c|c|c|}
\hline Age group & Year & Group & Mean & $\begin{array}{l}\text { Standard } \\
\text { deviation }\end{array}$ & Median & Percentile 25 & Percentile 75 \\
\hline \multirow[t]{10}{*}{ All ages } & \multirow[t]{2}{*}{$\mathrm{Y} 1$} & Case & $£ 1,327$ & $£ 2,114$ & $£ 890$ & $£ 427$ & $£ 1,742$ \\
\hline & & Control & $£ 328$ & $£ 2,248$ & $£ 69$ & $£ 0$ & $£ 214$ \\
\hline & \multirow[t]{2}{*}{ Y2 } & Case & $£ 1,196$ & $£ 2,228$ & $£ 770$ & $£ 302$ & $£ 1,544$ \\
\hline & & Control & $£ 337$ & $£ 2,215$ & $£ 65$ & $£ 0$ & $£ 208$ \\
\hline & \multirow[t]{2}{*}{ Y3 } & Case & $£ 1,148$ & $£ 3,749$ & $£ 735$ & $£ 267$ & $£ 1,459$ \\
\hline & & Control & $£ 316$ & $£ 1,459$ & $£ 64$ & $£ 0$ & $£ 197$ \\
\hline & \multirow[t]{2}{*}{ Y4 } & Case & $£ 1,126$ & $£ 3,535$ & $£ 673$ & $£ 235$ & $£ 1,439$ \\
\hline & & Control & $£ 325$ & $£ 1,531$ & $£ 64$ & $£ 0$ & $£ 201$ \\
\hline & \multirow[t]{2}{*}{ Y5 } & Case & $£ 1,112$ & $£ 4,137$ & $£ 632$ & $£ 196$ & $£ 1,420$ \\
\hline & & Control & $£ 361$ & $£ 2,103$ & $£ 65$ & $£ 0$ & $£ 211$ \\
\hline \multirow{10}{*}{$\begin{array}{l}\text { Aged } 6 \text { to } 17 \text { years } \\
\text { at index date }\end{array}$} & \multirow[t]{2}{*}{$\mathrm{Y} 1$} & Case & $£ 1,290$ & $£ 2,119$ & $£ 879$ & $£ 425$ & $£ 1,689$ \\
\hline & & Control & $£ 315$ & $£ 2,354$ & $£ 64$ & $£ 0$ & $£ 198$ \\
\hline & \multirow[t]{2}{*}{ Y2 } & Case & $£ 1,162$ & $£ 2,195$ & $£ 753$ & $£ 296$ & $£ 1,506$ \\
\hline & & Control & $£ 333$ & $£ 2,332$ & $£ 64$ & $£ 0$ & $£ 199$ \\
\hline & \multirow[t]{2}{*}{ Y3 } & Case & $£ 1,124$ & $£ 3,917$ & $£ 708$ & $£ 264$ & $£ 1,428$ \\
\hline & & Control & $£ 308$ & $£ 1,506$ & $£ 62$ & $£ 0$ & $£ 191$ \\
\hline & \multirow[t]{2}{*}{ Y4 } & Case & $£ 1,116$ & $£ 3,712$ & $£ 664$ & $£ 236$ & $£ 1,412$ \\
\hline & & Control & $£ 325$ & $£ 1,575$ & $£ 64$ & $£ 0$ & $£ 201$ \\
\hline & \multirow[t]{2}{*}{ Y5 } & Case & $£ 1,105$ & $£ 4,377$ & $£ 612$ & $£ 186$ & $£ 1,385$ \\
\hline & & Control & $£ 372$ & $£ 2,227$ & $£ 65$ & $£ 0$ & $£ 213$ \\
\hline \multirow{10}{*}{$\begin{array}{l}\text { Aged } \geq 18 \text { years } \\
\text { at index date }\end{array}$} & \multirow[t]{2}{*}{ Y1 } & Case & $£ 1,844$ & $£ 2,118$ & $£ 1,185$ & $£ 648$ & $£ 2,365$ \\
\hline & & Control & $£ 550$ & $£ 1,460$ & $£ 130$ & $£ 31$ & $£ 427$ \\
\hline & \multirow[t]{2}{*}{ Y2 } & Case & $£ 1,450$ & $£ 1,616$ & $£ 1,111$ & $£ 385$ & $£ 1,969$ \\
\hline & & Control & $£ 509$ & $£ 1,091$ & $£ 116$ & $£ 23$ & $£ 419$ \\
\hline & \multirow[t]{2}{*}{ Y3 } & Case & $£ 1,455$ & $£ 2,157$ & $£ 886$ & $£ 546$ & $£ 1,597$ \\
\hline & & Control & $£ 604$ & $£ 1,388$ & $£ 111$ & $£ 0$ & $£ 422$ \\
\hline & \multirow[t]{2}{*}{ Y4 } & Case & $£ 1,512$ & $£ 2,077$ & $£ 894$ & $£ 417$ & $£ 1,873$ \\
\hline & & Control & $£ 660$ & $£ 2,087$ & $£ 96$ & $£ 0$ & $£ 372$ \\
\hline & \multirow[t]{2}{*}{ Y5 } & Case & $£ 1,401$ & $£ 1,439$ & $£ 1,058$ & $£ 265$ & $£ 2,136$ \\
\hline & & Control & $£ 515$ & $£ 952$ & $£ 118$ & $£ 19$ & $£ 495$ \\
\hline
\end{tabular}

In our study, the diagnosed prevalence of ADHD in children age $6-17$ years old increased from 192.4 to 506.4 per100k between 1998 and 2007. An increasing incidence rate was also observed between 1998 (39.3 per100k) and 2007 (79.0 per100k). An increase in the prevalence of ADHD has been reported in the USA between 1997 and 2007 [41,46]. Since 2007, the incidence and prevalence rates have decreased, suggesting that recognition rates may have peaked for the time being. This is broadly in line with the findings of the most recent NHS Scotland audit [42] and coincides with the publication of the NICE guidelines, although we do not expect this to have resulted in a decrease in the recognition of ADHD [16].
A systematic review with meta-analysis has suggested that the prevalence of ADHD declines with age (although the strict application of DSM-IV criteria designed for use in children may have led to an underestimation of prevalence in the adults) [47]. However, many people do continue to have significant ADHD-related impairments as adults [16]. A meta-analysis reported that the rate of persistence of a full DSM-IV diagnosis of ADHD was 15\% at the age of 25 years, but when those patients fulfilling the DSM-IV definition of ADHD in partial remission were included, the rate of persistence increased to approximately $65 \%$ [48]. It has been estimated that this level of persistence equates to an estimated prevalence of $0.6-1.2 \%$ of adults by the age of 25 [16]. Our estimate of less than 
$0.02 \%$ prevalence in adults in 2009 (approximately 7,800 adults with ADHD in the UK [49]) is therefore much lower than expected [47,50], suggesting that the underrecognition of ADHD in adults exceeds that for children and adolescents. One possible explanation for this low prevalence rate could be that clinicians in the UK have only been diagnosing children over the last 20 years or so. As a consequence most adults were not diagnosed as children and, as services for adults are still not generally available, they are not yet getting diagnosed in large numbers as adults. Also, many adolescents are not transitioned to adult services. A study using data from GPRD identified that, for people aged 15-21 years between 1999-2006, prevalence of prescribing of ADHD medication decreased with increasing age but increased with increasing calendar year [43]. During the study period, we found a large increase in the prevalence of ADHD in adults (1.4 to 16.1 per 100,000 between 1998 and 2009), suggesting that either ADHD is now being increasingly recognised in adults or that children with a diagnosis of ADHD have grown and are still recognised to have the condition as adults.

The magnitude of the difference in annual mean costs was surprising. Prescription costs in year 1 were higher for cases compared to controls ( $£ 308$ and $£ 37$, respectively), largely due to the cost of ADHD medicines. NICE guidance indicates that drug treatment should be first line when ADHD is severe and can be considered for moderate ADHD and impairment in school-aged children and young adults when non-pharmacological approaches are unsuccessful [16]. In adults, drug treatment is recommended by NICE as first line unless the patient prefers psychological treatment. Drug treatment is not recommended for pre-school children. Within the context of significant under-recognition it is likely that those individuals receiving a diagnosis would be at the more severe end of the ADHD continuum. As a consequence medication treatment would often be considered the first-line treatment for all except the very young.

Numerous studies investigating the healthcare costs associated with ADHD have been carried out in the USA, but their applicability to the UK NHS is questionable due to different patterns of service provision. Using information available for the UK, some estimates have been made of the cost of certain aspects of healthcare for ADHD at the population level. For health, social care, and educational services, it has been estimated that the NHS spends approximately $£ 23$ million on initial specialist assessment of ADHD in England and Wales and $£ 14$ million on follow-up care over one year [51]. In addition, the NHS spent approximately $£ 8.5$ million, $£ 1.3$ million, and $£ 25.7$ million on prescriptions for atomoxetine, dexamfetamine, and methylphenidate, respectively, in 2010 [3]. It is likely that almost all of this would have been spent in the treatment of ADHD, although dexamfetamine and methylphenidate also have an unlicensed indication for narcolepsy [21]. Furthermore, the mean annual cost of health and social care and educational resources relating to ADHD per adolescent in the UK has been estimated as $£ 5,493$ (median $£ 2,327$ ), where $24 \%$ of this cost relates to health [52]. In addition, ADHD commonly occurs with other conditions such as learning disorders, conduct and oppositional disorders, Tourette's syndrome, bipolar disorder, anxiety and depression [16], and these conditions are likely to contribute to the higher healthcare costs observed for ADHD patients.

This study had inherent limitations. For cases where there was no prescription for an ADHD medication the requirement of two or more diagnoses was used in order to avoid selecting patients where the GP had recorded a provisional diagnosis of ADHD prior to referral for assessment by a specialist. However, this may have led to the exclusion of possible ADHD patients from the cost calculation and an underestimate of the incidence and prevalence rates. The care pathway for ADHD differs in comparison to many chronic conditions and will vary by site. Once the condition has been stabilised, GPs often prescribe drugs for ADHD under shared-care protocols. Prescriptions written in secondary care are not recorded in CPRD and could not be costed. Any underestimation of resource use and the related financial cost will disproportionately impact on the ADHD group and therefore the differences reported may underestimate the true difference. Those patients who are more difficult to stabilise may be less well recorded in CPRD as more of their healthcare may be provided in secondary care. In addition, our study index date may vary between patients from the date of first presentation to the GP, the date of referral back to the GP from secondary care, or the date of the first GP prescription for an ADHD medication. CPRD includes GP practices from all four UK regions and is therefore generalisable to the whole of the UK. On the other hand, the linked HES data is exclusively English, which could suggest that the healthcare cost estimates are generalisable to England only. However, the patients registered in the linked practices have been shown to be representative of the whole CPRD population [53].

Regarding the estimation of prevalence, a patient had to have received a diagnosis of ADHD or a prescription for a medication for ADHD both prior to and after 1st July each year. Although a washout period of 12 months was applied, the time between the mid-year point and the last collection date for the database becomes shorter for the more recent years and this may have contributed to the reduction in prevalence rates since 2007. However, this method was selected since clinical records in CPRD cannot be used to determine when a patient stops experiencing ADHD. The calculation of incidence is 
sensitive to the method used to calculate the denominator. Although, for this study, patients need not necessarily have had contact with their general practice to be included in the patient-years estimate. An underestimation in the incidence and prevalence rates could also have occurred if diagnoses were not accurately recorded in CPRD. The validity of medical diagnoses in CPRD have been confirmed in several studies [54,55]. GPs in the UK act as gatekeepers, and referrals to and outpatient letters from secondary care should be recorded in CPRD. However, ADHD diagnoses may be less well recorded than other conditions diagnosed and treated exclusively in primary care.

\section{Conclusion}

In summary, the prevalence of diagnosed ADHD in the UK was notably lower than in reports that used screening. Costs in those with ADHD were more than four times higher than in those without ADHD.

\section{Additional file}

Additional file 1: Figure S1. Study Numbers.

\section{Abbreviations}

ADHD: Attention deficit/hyperactivity disorder; CPRD: Clinical Practice Research Datalink; DSM: Diagnostic and Statistical Manual of Mental Disorders; GP: General Practitioner; HRG: Healthcare Resource Group; NHS: National Health Service; NIC: Net ingredient cost; NICE: National Institute for Health and Care Excellence; PCA: Prescription Cost Analyses; PSSRU: Personal Social Services Research Unit.

\section{Competing interests}

CLIM and CDP have been and SEH and SJJ are employed by Pharmatelligence, a research consultancy receiving funding from pharmaceutical companies. SEH is employed by Alliance Boots. CDP has consulted for the following manufacturers of diabetic pharmaceuticals: Astellas, BMS, Ferring, Lilly, Medtronic, Novo Nordisk, Sanofi-Aventis, and Wyeth. DC has received research grants from various health-related organisations, including European Union FP7, the National Institute for Health Research, Shire, and Vifor; consults for Shire; has been on advisory boards for Flynn Pharma, Janssen, Lilly, Medice, Novartis, Shire, and Vifor; has received royalties from Oxford University Press; and has received payment for lectures from Flynn Pharma, Janssen, Lilly, Shire, and Vifor. CJC has received research grants from various health-related organisations including Abbott, Astellas, Diabetes UK, the Engineering and Physical Sciences Research Council, the EASD, Ferring, GSK, Lilly, the Medical Research Council, Medtronic, MSD, the National Health Service, Pfizer, Sanofi-Aventis, Shire, and Wyeth; and consults for Amylin, Aryx, Astellas, Boehringer Ingelheim, BMS, Diabetes UK, Eisel, Ferring, GSK, Ipsen, Lilly, Medtronic, MSD, Pfizer, SanofiAventis, Takeda, and Wyeth.

\section{Authors' contribution}

The authors contributed the following: CJC conceived the study. CJC, CDP, CLIM, and SEH contributed to study design. SEH and CLIM analysed the data. SEH, CJC, DC, and CDP interpreted the data. SEH drafted the manuscript. SJJ provided data preparation and technical support. CJC, SEH, and DC were involved in the writing and reviewing of the report. CJC had overall responsibility for the study and is overall guarantor. JS and PH of Shire Development LLC provided comments on the outline and the initial draft of the manuscript, but the final content of this manuscript, the ultimate interpretation, and the decision to submit it for publication to the Child and Adolescent Psychiatry and Mental Health was made by the authors independently. All authors, external and internal, had full access to all of the data (including statistical reports and tables) in the study and can take responsibility for the integrity of the data and the accuracy of the data analysis. All authors read and approved the final manuscript.

\section{Funding}

This research was funded by Shire Development LLC.

\section{Author details}

${ }^{1}$ Primary Care and Public Health, School of Medicine, The Pharma Research Centre, Cardiff Medicentre, Cardiff University, Cardiff CF14 4UJ, UK. ${ }^{2}$ Global Epidemiology, Pharmatelligence, Cardiff Medicentre, Cardiff CF14 4UJ, UK. ${ }^{3}$ Division of Neuroscience, Medical Research Institute, University of Dundee, Dundee DD1 9SY, UK.

Received: 26 April 2013 Accepted: 2 October 2013

Published: 11 October 2013

\section{References}

1. Ford T, Goodman R, Meltzer H: The British Child and Adolescent Mental Health Survey 1999: the prevalence of DSM-IV disorders. J Am Acad Child Psy 2003, 42:1203-1211.

2. Prescribing \& medicines: medicines used in mental health. Financial years 2001/02 - 2010/11. http://www.isdscotland.org/Health-Topics/ Prescribing-and-Medicines/Publications/2011-09-27/2011-09-27PrescribingMentalHealth-Summary.pdf?96236819029.

3. Hospital prescribing, England. 2010. http://www.ic.nhs.uk/pubs/hospre10

4. Harpin $V$ a: The effect of ADHD on the life of an individual, their family, and community from preschool to adult life. Arch Dis Child 2005, 90(Suppl 1):i2-i7

5. Bagwell CL, Molina BS, Pelham WE, Hoza B: Attention-deficit hyperactivity disorder and problems in peer relations: predictions from childhood to adolescence. J Am Acad Child Adolesc Psychiatry 2001, 40:1285-1292.

6. Kadesjo B, Gillberg C: The comorbidity of ADHD in the general population of Swedish school-age children. J Child Psychol Psychiat 2001, 42:487-492.

7. Johnston C, Mash EJ: Families of children with attention-deficit/hyperactivity disorder: review and recommendations for future research. Clin Child Fam Psychol Rev 2001, 4:183-207.

8. Ray GT, Levine P, Croen LA, Bokhari F, Hu T-W, Habel L: Attention-deficit/ hyperactivity disorder in children: excess costs before and after initial diagnosis and treatment cost differences by ethnicity. Arch Pediatr \& Adolesc Med 2006, 160:1063-1069.

9. Guevara J, Lozano P, Wickizer T, Mell L, Gephart H: Utilization and cost of health care services for children with attention-deficit/hyperactivity disorder. Pediatrics 2001, 108:71-78.

10. Leibson C, Katusic S, Barbaresi WJ, Ransom J, Brien PCO: Use and costs of medical care for children attention-deficit/hyperactivity disorder. JAMA 2001, 285:60-66.

11. Chan E, Zhan C, Homer CJ: Health care Use and costs for children with attention-deficit/hyperactivity disorder. Arch Pediat Adol Med 2002, 156:504-511.

12. Pelham WE, Foster EM, Robb J a: The economic impact of attention-deficit /hyperactivity disorder in children and adolescents. Ambul Pediatr 2007, 7(1 Suppl):121-131.

13. Matza LS, Paramore C, Prasad M: A review of the economic burden of ADHD. Cost Eff Resour Alloc 2005, 3:5.

14. Birnbaum H, Kessler R, Lowe S, Secnik K, Greenberg P, Leong S, Swensen A Costs of attention deficit-hyperactivity disorder (ADHD) in the US: excess costs of persons with ADHD and their family members in 2000. Curr Med Res Opin 2005, 21:195-206.

15. Hakkaart-van Roijen L, Zwirs BWC, Bouwmans C, Tan SS, Schulpen TWJ, Vlasveld L, Buitelaar JK: Societal costs and quality of life of children suffering from attention deficient hyperactivity disorder (ADHD). Eur Child Adoles Psy 2007, 16:316-326.

16. ADHD: diagnosis and management of $A D H D$ in children, young people and adults. NICE Clinical Guideline 72. http://www.nice.org.uk/nicemedia/ pdf/adhdfullguideline.pdf.

17. Use of ADHD drugs "increases by $50 \%$ in six years". http://www.bbc.co. uk/news/health-23674235. 
18. ADHD services over Scotland final report. http://www.healthcareimprove mentscotland.org/our_work/mental_health/adhd_service_improvement/ stage_3_adhd_final_report.aspx.

19. Clinical practice research datalink. http://www.cprd.com/intro.asp.

20. Committee on Safety of Medicines and Medicines Control Agency: Volital (Pemoline) has been withdrawn. Current Problems in Pharmacovigilance 1997, 23:10

21. British National Formulary (online). http://www.medicinescomplete.com.

22. Prescriptions cost analysis - England. 2011. http://www.ic.nhs.uk/pubs/ prescostanalysis2011.

23. Prescribing. http://www.hscic.gov.uk/prescribing.

24. Prescription cost analysis, England. 2010. http://www.ic.nhs.uk/catalogue/ PUB02274/pres-cost-anal-eng-2010-apx.pdf.

25. HM Treasury: Economic data and tools. Latest figures. http://www.hmtreasury.gov.uk/data_gdp_fig.htm.

26. Tariff information: confirmation of payment by results $(\mathrm{PbR})$ arrangements for 2010-2011. http://data.gov.uk/dataset/payment-byresults-2010-11-national-tariff-information.

27. NHS reference costs 2010-2011. http://www.dh.gov.uk/en/ Publicationsandstatistics/Publications/PublicationsPolicyAndGuidance/ DH_131140.

28. Health Statistics Wales 2011. http://wales.gov.uk/topics/statistics/ publications/publication-archive/health2011/?lang=en.

29. NHS National Services Scotland. http://www.isdscotland.org/.

30. NHS pathology: pathology solutions. http://www.nhspathology.fph.nhs.uk/.

31. Unit costs of health and social care. 2011. http://www.pssru.ac.uk/archive/ pdf/uc/uc2011/uc2011.pdf.

32. GP workload survey. http://www.ic.nhs.uk/pubs/gpworkload.

33. Downloads: costing. http://www.ic.nhs.uk/casemix/costing.

34. NHS Reference Costs 2009-2010. https://www.gov.uk/government/ publications/nhs-reference-costs-2009-2010.

35. Polanczyk G, De Lima MS, Horta BL, Biederman J, Rohde LA: The worldwide prevalence of ADHD: a systematic review and metaregression analysis. Am J Psychiatry 2007, 164:942-948.

36. Sayal K, Taylor E, Beecham J, Byrne P: Pathways to care in children at risk of attention-deficit hyperactivity disorder. Br J Psychiatry 2002, 181:43-48.

37. Sayal K, Goodman R, Ford T: Barriers to the identification of children with attention deficit/hyperactivity disorder. J Child Psychol Psychiatry 2006, 47:744-750.

38. Jick H, Kaye JA, Black C: Incidence and prevalence of drug-treated attention deficit disorder among boys in the UK. Br J Gen Pract 2004, 54:345-347.

39. Klasen H, Goodman R: Parents and GPs at cross-purposes over hyperactivity: a qualitative study of possible barriers to treatment. Br J Gen Pract 2000, 50:199-202.

40. Froehlich TE, Lanphear BP, Epstein JN, Barbaresi WJ, Katusic SK, Kahn RS: Prevalence, Recognition, and Treatment of Attention-Deficit /Hyperactivity Disorder in a National Sample of US Children. Arch Paediat Adol Med 2007, 161:857-864.

41. Morbidity and Mortality Weekly Report (MMWR). Increasing Prevalence of Parent-Reported Attention-Deficit/Hyperactivity Disorder Among Children - United States, 2003 and 2007. http://www.cdc.gov/mmwr/ preview/mmwrhtml/mm5944a3.htm.

42. Attention Deficit and Hyperkinetic Disorders - Services Over Scotland (ADHD-SOS) Follow-up Review. http://www.healthcareimprovement scotland.org/his/idoc.ashx?docid=c3c72452-cb24-4179-bdba-13be65b74c3d \&version $=-1$

43. McCarthy S, Asherson P, Coghill D, Hollis C, Murray M, Potts L, Sayal K, De Soysa R, Taylor E, Williams T, Wong ICK: Attention-deficit hyperactivity disorder: treatment discontinuation in adolescents and young adults. Br J Psychiatry 2009, 194:273-277.

44. Kooij J, Buitelaar J, Van den Oord E, Furer J, Rijnders C, Hodiamont P: Internal and external validity of Attention-Deficit Hyperactivity Disorder in a population-based sample of adults. Psychol Med 2004, 34:1-11.

45. Berry CA, Shaywitz SE, Shaywitz BA: Girls with attention deficit disorder: a silent minority? A report on behavioral and cognitive characteristics. Pediatrics 1985, 76:801-809.

46. Pastor PN, Reuben $C$ a: Diagnosed attention deficit hyperactivity disorder and learning disability: United States, 2004-2006. Vital Health Stat 2008, $10: 1-14$.
47. Simon V, Czobor P, Bálint S, Mészáros A, Bitter I: Prevalence and correlates of adult attention-deficit hyperactivity disorder: meta-analysis. Br J Psychiatry 2009, 194:204-211.

48. Faraone SV, Biederman J, Mick E: The age-dependent decline of attention deficit hyperactivity disorder: a meta-analysis of follow-up studies. Psychol Med 2006, 36:159-165.

49. Office for National Statistics: Population estimates quinary age groups for UK constituent countries - mid 1971 to mid 2010. http://www.ons.gov. uk/ons/rel/pop-estimate/population-estimates-for-uk-england-and-walesscotland-and-northern-ireland/population-estimates-timeseries-1971-tocurrent-year/index.html.

50. Kessler RC, Adler L, Barkley R, Biederman J, Conners CK, Demler O, et al: The prevalence and correlates of adult ADHD in the United States: results from the National Comorbidity Survey Replication. Am J Psychiat 2006, 163:716-723.

51. King S, Griffin S, Hodges Z, Weatherly H, Asseburg C, Richardson G, Golder S, Taylor E, Drummond M, Riemsma R: A systematic review and economic model of the effectiveness and cost-effectiveness of methylphenidate, dexamfetamine and atomoxetine for the treatment of attention deficit hyperactivity disorder in children and adolescents. Health Technol Asses 2006, 10:1-146.

52. Telford C, Green C, Logan S, Langley K, Thapar A, Ford T: Estimating the costs of ongoing care for adolescents with attention-deficit hyperactivity disorder. Soc Psychiatry Psychiatr Epidemiol 2013, 48:337-344.

53. Gallagher A, Puri S, Van Staa T: Linkage of the General Practice Research Database (GPRD) with other data sources. Pharmacoepidemiol Drug Saf 2011, 20:S1-S364.

54. Khan NF, Harrison SE, Rose PW: Validity of diagnostic coding within the General Practice Research Database : a systematic review. Brit J Gen Pract 2010, 60:e128-e136.

55. Herrett E, Thomas SL, Schoonen WM, Smeeth L, Hall AJ: Validation and validity of diagnoses in the General Practice Research Database: a systematic review. Brit J Clin Pharmaco 2010, 69:4-14.

doi:10.1186/1753-2000-7-34

Cite this article as: Holden et al:: The prevalence and incidence, resource use and financial costs of treating people with attention deficit/hyperactivity disorder (ADHD) in the United Kingdom (1998 to 2010). Child and Adolescent Psychiatry and Mental Health 2013 7:34.

\section{Submit your next manuscript to BioMed Central and take full advantage of:}

- Convenient online submission

- Thorough peer review

- No space constraints or color figure charges

- Immediate publication on acceptance

- Inclusion in PubMed, CAS, Scopus and Google Scholar

- Research which is freely available for redistribution 